
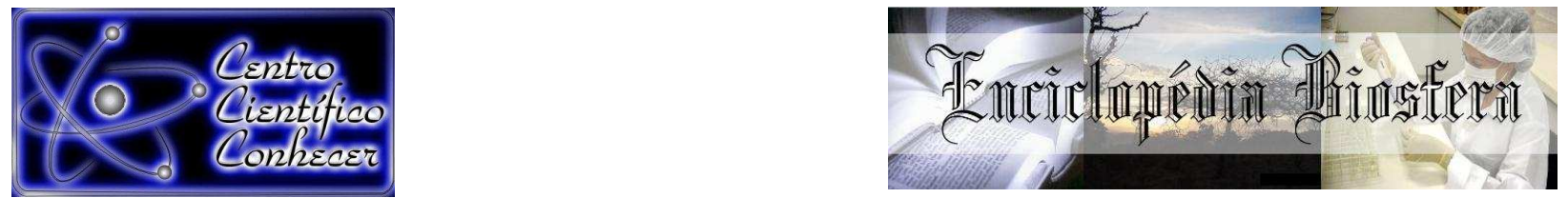

\title{
PERFIL FITOQUÍMICO E SUSCETIBILIDADE ANTIBACTERIANA DA Lafoensia pacari Saint-Hilaire (LYTHRACEAE) e Persea americana Mill (LAURACEAE) DO CERRADO BRASILEIRO
}

\footnotetext{
Alexandra Barbosa da Silva ${ }^{1}$; Nágila Fernanda Moreira Melo $^{2}$; José Ribamar Nogueira $^{3}$; Luciano Nonato Carvalho Martins ${ }^{4}$; Alvaro Carlos Galdos-Riveros ${ }^{5}$

${ }^{1}$ Laboratorista dos Laboratórios da Saúde da Faculdade Anhanguera de Brasília

${ }^{2}$ Biomédica, formada pela Faculdade Anhanguera de Brasília

${ }^{3}$ Laboratorista da Universidade Católica de Brasília

${ }^{4}$ Laboratorista dos Laboratórios de Farmacologia Molecular Universidade de Brasília

${ }^{5}$ Docente do Instituto de Ciências da Saúde, Universidade Federal de Mato Grosso, Sinop

(alvarogaldos@usp.br)

Recebido em: 03/10/2016 - Aprovado em: 21/11/2016 - Publicado em: 05/12/2016

DOI: 10.18677/EnciBio_2016B 118
}

\begin{abstract}
RESUMO
O Brasil possui uma grande diversidade de espécies vegetais com valor medicinal, somada ao vasto conhecimento popular sobre o uso das plantas e recursos tecnológicos capazes de provar cientificamente a ação das plantas. A Lafoensia pacari popularmente conhecida como: mangaba brava, pacari e dedaleira, entre outros nomes usados na medicina popular. Os seus metabólitos secundários fazem com que a planta apresente atividade antifúngica e bactericida. São utilizadas tradicionalmente pela população como emagrecimento, tratamento de coceiras, feridas, dores de estômago, úlcera, anti-inflamatório e cicatrizante. O consumo do fruto da Persea americana M. conhecida como abacate serve no tratamento de enfermidades como diabetes, cardiopatias, dislipidemias, hepatopatias e como redutor de colesterol. Entre as suas principais propriedades terapêuticas tem-se a antimicrobiana, antioxidante, antiplasmodium falciparum, antiplaquetário/antitrombótico e antileishmaniose. O presente trabalho avaliará o perfil fitoquímico dos extratos aquoso, etanólico e hidroalcoólico das folhas de Lafoensia pacari e a semente da Persea americana, como também a ação antimicrobiana frente a Staphylococcus aureus e Salmonella typhimurium. Na análise fitoquímica demonstrou a presença de taninos, saponinas, alcaloides, flavonoides e glicosídeos. A análise antibacteriana demonstrou que os extratos etanólico e hidroalcoólico apresentaram ação antimicrobiana significativa contra Staphylococcus aureus unicamente. Esses compostos bioativos possibilitaram o efeito antibacteriano dos extratos etanólico e hidroalcoólico, devido à relação solutosolvente que permitiu um maior aproveitamento de sua ação terapêutica frente a Staphylococcus aureus.
\end{abstract}

PALAVRAS-CHAVE: Bactericida, Fitoterapia, Plantas Medicinais.

\section{PHYTOCHEMICAL PROFILE AND SUSCEPTIBILITY OF ANTIBACTERIAL of Lafoensia pacari Saint-Hilaire (Lythraceae) and Persea americana Mill (LAURACEAE) BRAZILIAN CERRADO}

\section{ABSTRACT}

The Brazil has a great diversity of plant species with medicinal value, added to the vast popular knowledge about the use of plants and technological resources able to 
scientifically prove the action of plants. The Lafoensia pacari popularly known as mad mangaba, pacari and foxglove, among other names used in folk medicine. Your secondary metabolites cause the plant present antifungal and antibacterial activity. Are traditionally used by the population as weight loss, treatment of itching, sores, stomach pain, ulcer, anti-inflammatory and healing. The consumption of the fruit of Persea americana M. known as avocado serve in the treatment of diseases such as diabetes, heart disease, dyslipidemia, liver diseases and as a cholesterol reducer. Among its main therapeutic properties have antimicrobial, antioxidant, falciparum antiplasmodium, antiplatelet / antithrombotic and antileishmaniose. This study will assess the phytochemical profile of aqueous, hydroalcoholic and ethanolic Leaves Lafoensia pacari and seed Persea americana, as well as the antimicrobial activity against Staphylococcus aureus and Salmonella typhimurium. In phytochemical analysis showed the presence of tannins, saponins, alkaloids, flavonoids and glycosides. Antimicrobial analysis showed that ethanol and hydro alcoholic extracts showed significant antimicrobial activity against Staphylococcus aureus only. These bioactive compounds enabled the antimicrobial effect of ethanol and hydroalcoholic extracts, due to solute-solvent ratio which allowed greater use of front therapeutic action Staphylococcus aureus.

KEYWORDS: Phytoterapy, antimicrobial, Medicinal herbs.

\section{INTRODUÇÃO}

O Brasil é considerado um dos países de maior diversidade biológica (MYERS et al., 2000). O cerrado é exemplo de bioma com tal diversidade comparado com outros biomas existente no país (REGO et al., 2009). Estudos desenvolvidos pela Organização Mundial de Saúde (OMS) mostram que aproximadamente $80 \%$ da população mundial utilizaram algum tipo de erva na busca de alívio de algum sintoma doloroso ou desagradável (QUEIROZ-SILVA et al., 2012).

O recuso das plantas para o tratamento de doenças é um ramo da medicina conhecido como fitoterapia. No bioma do Cerrado encontra-se a planta Lafoensia pacari conhecida como "dedaleira" utilizada na medicina popular, é considerada uma planta com potencial antimicrobiano (MUNDO 2007; QUEIROZ-SILVA et al., 2012).

O consumo do abacate auxilia no tratamento de doenças crônicas, especialmente as cardiopatias, diabetes, dislipidemias, hepatopatias, redutor de colesterol e propriedades contra o envelhecimento. Ademais, é rico em ácido oleico, vitamina $\mathrm{C}$, fibras, esteróis, sendo uma das maiores fontes de glutationa, um poderoso antioxidante com ação anticancerígena (CREDIDIO, 2008).

As pesquisas demonstram que na Persea americana contém fenóis, taninos, flavonóides, flavonas, entre outros. As análises de metais foram realizadas com a folha, o caule e o caroço e os resultados também foram bem parecidos, no qual encontrou-se cálcio, potássio, fósforo (SANTOS, 2014). O trabalho de MUNDO (2007) mostra que Lafoensia pacari tem glicosídeos nas folhas, outros autores mostraram que além de glicosídeos, outros metabólicos como saponinas também estão presentes (PORFÍLIO et al., 2008; SAMPAIO et al., 2011).

Trata-se de projeto de pesquisa de bancada que será realizado com utilização das folhas da Lafoensia pacari e do caroço da planta Persea Americana Breda M., para investigar propriedades antimicrobianas, pretendendo-se constatar, através da pesquisa in vitro, se efetivamente apresenta ação que auxilia no tratamento de infecções causadas por bactérias gram positivas e gram negativas. 
Diante do exposto, o objetivo deste estudo foi avaliar o perfil fitoquímico e atividade antimicrobiana nos extratos etanólico, hidroetanólico e aquoso das folhas da Lafoensia pacari e do caroço da planta Persea Americana Breda M. frente a bactérias gram positivas e gram negativas.

\section{Material vegetal}

\section{MATERIAL E MÉTODOS}

As amostras da Lafoensia pacari foram coletadas no município da cidade de Januária - Minas Gerais, retiradas no dia três de setembro de 2014, em fazendas da região. Enquanto que as sementes da Persea americana Breda M. foram coletadas do abacateiro da variedade "breda", na Chácara Vitória Régia no 01, Núcleo Rural Cascalheira, Brazlândia-DF. As duas espécies foram fotodocumentadas com auxílio de uma câmera Canon ${ }^{\circledR}$ A26 e preparada a exsicata que foi devidamente identificada pela Dra. Giovanna Caramashi e posteriormente depositada no herbário da Faculdade Anhanguera de Brasília com os números de registro: 12.1001 e 12.2002.

\section{Preparação dos extratos}

O material coletado foi secado em estufa (QUIMIS $\AA$ ) por 30 minutos a $45^{\circ} \mathrm{C}$. Previamente seco, foi submetido à trituração no microgranulador (LM- Lemaq, Mod. 061019110) e posteriormente foi empregada a técnica de maceração como método de extração. Utilizou-se $50 \mathrm{~g}$ de cada amostra para cada $150 \mathrm{~mL}$ de solvente. Para o extrato etanólico foram usados $150 \mathrm{~mL}$ de etanol $99,9 \%$, para o aquoso $200 \mathrm{~mL}$ água destilada e para hidroalcoólico 1:1 etanol 99,9\%/água destilada. Após agitação manual de sete dias as misturas foram filtradas e concentradas com auxílio de rotaevaporador sob vácuo (FISATOM® Mod. 801). Desta forma os extratos aquosos, etanólico e hidroalcoólico foram obtidos e armazenados em frasco âmbar protegidos da luz e em seguida estocados em geladeira a uma temperatura de $4-8^{\circ} \mathrm{C}$ até 0 momento da utilização.

\section{Análise fitoquímica qualitativa}

Para a detecção de metabólitos secundários tais como flavonóides, esteróides/triterpenóides, taninos, saponinas, antraquinonas, alcalóides e glicosídeos foi utilizada a técnica de análise fitoquímica de acordo com MATOS (1997), HONDA (1990) e SIMÕES et al. (2010), COSTA (2002), KOKATE (2009) e BISWAS et al. (2013) na prospecção de constituintes químicos de extratos de plantas.

\section{Avaliação da susceptibilidade antimicrobiana}

Para este teste foi utilizada a metodologia in vitro de difusão em poços segundo SILVEIRA et al. (2009), utilizando as cepas bacterianas Gram positivas: Staphylococcus aureus (ATCC 25923) e Gram negativos: Salmonella Typhimurium (ATCC 123912).

As placas contendo ágar Mueller Hinton preparadas antecipadamente foram retiradas da geladeira até atingir a temperatura ambiente. Fizeram-se poços de 4 $\mathrm{mm}$ de diâmetro. Com um swab estéril, o inóculo bacteriano com turvação 0,5 da escala de Mc Farland foi distribuído uniformemente sobre a superfície do ágar, deixadas em repouso em temperatura ambiente, por aproximadamente três minutos. Dispensou-se em cada poço devidamente identificado, $50 \mu \mathrm{L}$ de cada concentração do extrato $(1: 1,1: 2,1: 4,1: 8,1: 16$ e 1:32), utilizando-se uma pipeta automática, sendo uma placa para cada concentração testada. 
As placas foram incubadas em estufa a $37 \pm 1^{\circ} \mathrm{C}$ por 24 horas. Mediu-se em milímetros o halo de inibição do crescimento, utilizando um paquímetro manual. Os testes foram realizados em triplicata e em dias diferentes. Como controle negativo foi utilizada água destilada e como controle positivo o antibiótico amoxicilina.

\section{RESULTADOS E DISCUSSÃO}

De acordo com SIMÕES et al. (2010), as plantas têm sido desde a antiguidade, um recurso ao alcance do ser humano. Durante milênios o homem empiricamente aprofundou seus conhecimentos a fim de buscar a melhoria nas condições de alimentação e cura de enfermidades, demonstrando uma estreita interrelação entre o uso das plantas e a evolução.

As análises fitoquímicas fornecem informações relevantes referentes à presença de compostos bioativos (metabólitos secundários) nas plantas, que seriam isolados para a produção de novos fitoterápicos. Na análise fitoquímica dos diferentes extratos da Lafoensia pacari e a Persea americana Breda M. confirmaram a presença dos seguintes metabólitos: glicosídeos, saponinas, taninos, alcalóides e flavonoides. Em nenhum dos tipos de extratos das duas amostras foram encontradas antraquinonas e esteroides/triterpenoides (Tabela1).

TABELA 1-Composição fitoquímica da Lafoensia pacari e a Persea americana M.

\begin{tabular}{|c|c|c|c|}
\hline Metabólitos & Etanólico & Hidroetanólico & Aquoso \\
\hline \multicolumn{4}{|l|}{ Lafoensia pacari } \\
\hline Saponinas & --- & ++++ & ++++ \\
\hline Antraquinonas & $-\ldots$ & $-\cdots$ & $-\cdots$ \\
\hline Glicosídeos & ++++ & ++++ & ++++ \\
\hline Taninos & ++++ & ++++ & ++++ \\
\hline Alcalóides & ++++ & ++++ & ++++ \\
\hline Flavonoide & $-\ldots$ & ++++ & ++++ \\
\hline Esteroides/Triterpenoides & $-\ldots$ & - - - & $-\cdots$ \\
\hline \multicolumn{4}{|c|}{ Persea americana } \\
\hline Saponinas & --- & ++++ & $-\cdots+$ \\
\hline Antraquinonas & --- & ---- & $-\cdots$ \\
\hline Glicosídeos & ++++ & ++++ & ++++ \\
\hline Taninos & ++++ & ++++ & ++++ \\
\hline Alcaloides & ++++ & +++- & +++- \\
\hline Flavonoides & ++++ & ++++ & ++++ \\
\hline Esteroides/Triterpenoides & $-\cdots$ & $-\cdots$ & $-\cdots$ \\
\hline
\end{tabular}

Nota: ++++ fortemente positivo, ++ moderadamente positivo, + positivo e - negativo.

Os glicosídeos são flavonóis glicosilados descritos como bioprodutos de espécies deste gênero são geralmente derivados do kanferol e quercetina, o mesmo ocorrendo também com os derivados metilados e acilados (MELO, 2005). O trabalho de MUNDO (2007) mostra que Lafoensia. pacari apresenta glicosídeos nas folhas, outros autores mostraram que além de glicosídeos, outros metabólitos como saponinas também estão presentes (PORFÍLIO et al., 2008; SAMPAIO et al., 2011).

Os taninos são classificados em dois grupos os taninos condensados, e os taninos hidrolisáveis, os taninos encontrados foram os hidrolisáveis. Lafoensia pacari é hidrolisável demonstrado por SAMPAIO (2010). O trabalho de MONTEIRO et al., (2014) avaliou a quantidade de taninos totais nas espécies arbóreas, entre estas a L. pacari. Como esperado o tanino foi confirmado em todos os extratos. 
Os taninos possuem atividade adstringente porque quebram as proteínas e formam um filme impermeável, sendo usados como protetores de mucosas e tecidos descobertos. São antissépticos, antimicrobianos (lesam a parede celular de protozoários, fungos e bactérias), cicatrizante e hemostático (SIMÕES et al., 2010).

O estudo sobre ação antimicrobiana presente em plantas é importante para a descoberta de novos fármacos e/ou garantir a segurança de substâncias já existentes (SILVEIRA et al., 2009). Algumas plantas têm a capacidade de produzir substâncias para a sua própria defesa, é observado que estas mesmas substâncias podem ser identificadas e utilizadas em benefício do homem (YUNES \& CALIXTO, 2001), pode-se citar como exemplo a ação antimicrobiana desenvolvida por taninos, terpenos e flavonóides (MATIAS et al., 2010).

Uma das ações atribuídas a aldeídos-terpenos é a inibição de proteinase (MEISNER et al., 1978). Esta ação pode estar relacionada com a atividade antibiótica pela diminuição de aminoácidos causados pela intervenção na digestão das proteínas o que prejudica a síntese da mesma. Desta forma o microrganismo não teria uma das substâncias necessárias para sua sobrevivência (SILVA FILHO \& FALCO, 2000).

A atividade antimicrobiana exercida pelos flavonóides pode ser explicada pela capacidade deste metabólito secundário de se ligar a parede celular da bactéria através da formação de complexos com proteínas solúveis (MATIAS et al., 2010). Nos testes antibacterianos a Lafoensia pacari e a Persea americana M. apresentaram atividade significativa frente a cepa de Staphylococcus aureus unicamente. O que sugere que os compostos bioativos encontram-se em menor quantidade no combate das bactérias gram negativas.

TABELA 2 - Diluições dos extratos da Lafoensia pacari e Persea americana M. e zona de inibição ( $\mathrm{mm})$

\begin{tabular}{|c|c|c|c|}
\hline Diluição & $\begin{array}{l}\text { Etanólico } \\
(\mathrm{mm})\end{array}$ & $\begin{array}{l}\text { Hidroalcoólico } \\
(\mathrm{mm})\end{array}$ & $\begin{array}{c}\text { Aquoso } \\
(\mathrm{mm})\end{array}$ \\
\hline \multicolumn{4}{|c|}{ Lafoensia pacari } \\
\hline $1: 1$ & 36 & 33 & 33 \\
\hline $1: 2$ & 34 & 31 & 30 \\
\hline $1: 4$ & 30 & 27 & 24 \\
\hline $1: 8$ & 30 & 25 & - \\
\hline 1:16 & 27 & 23 & 21 \\
\hline $1: 32$ & 23 & 22 & 18 \\
\hline $1: 64$ & 22 & 20 & - \\
\hline \multicolumn{4}{|c|}{ Persea americana } \\
\hline $1: 1$ & 18 & 14 & - \\
\hline $1: 2$ & 15 & 12 & - \\
\hline $1: 4$ & 14 & 10 & - \\
\hline $1: 8$ & 11 & 8 & - \\
\hline 1:16 & 8 & 6 & - \\
\hline $1: 32$ & 5 & - & - \\
\hline $1: 64$ & - & - & - \\
\hline
\end{tabular}

\section{CONCLUSÃO}

O extrato etanólico e hidroalcoólico apresentaram atividade antimicrobiana frente a Staphylococcus aureus nas duas amostras testadas. Enquanto que o extrato aquoso somente apresentou atividade na Lafoensia pacari. Estas espécies apresentaram ser somente efetivas frente a Staphylococcus aureus. $\mathrm{O}$ isolamento 
dos principais princípios ativos constituirá um candidato essencial na procura por novos fitoterápicos frente às infecções nos hospitais e na comunidade.

\section{AGRADECIMENTOS}

Os autores agradecem à Farm. Evalina Costa de Souza e a toda a equipe técnica dos laboratórios de Saúde da Faculdade Anhanguera de Brasília pelo apoio na parte experimental e técnico-científica oferecida.

\section{REFERÊNCIAS}

BISWAS, B.; ROGERS, K.; MCLAUGHLIN, F,; DANIELS, D.; YADAV A. Antimicrobial activities of leaf extratcts of Guava (Psidium guajava L.) on two GramNegative and Gram-Positive bacteria. International Journal of Microbiology., v. 2013, p. 1 - $\quad 7,2013$. Disponivél em: < https://www.hindawi.com/journals/ijmicro/2013/746165/> doi: http://dx.doi.org/10.1155/2013/746165

COSTA, A. F. Farmacognosia. 6 ed. Lisboa: Fundação Calouste Gulbenkian, 2002, p.658

CREDIDIO, E.V. Alimentos funcionais na Nutrologia Médica, 4⿳亠丷a ed. Itu: Editora Ottoni, 2008, 592 p.

HONDA, N. K. Estudo químico de plantas de Mato Grosso do Sul I: triagem fitoquímica. Revista Científica Cultural., v. 1, n. 5, p. 37-46, 1990. Disponível em: < https://scientiaplena.org.br/sp/article/viewFile/22/14>.

KOKATE, S. J. Extraction chromatographic separation of platinum (IV) from real samples and associated elements. Chinese Journal of Chromatographic., v. 27, n. 6, p. 809-814, 2009. Disponível em: < http://scholar.google.com.br/scholar_url?url=http://www.chromchina.com/CN/article/downloadArticleFile.do\%3FattachType\%3DPDF\%26id\%3D105 $81 \& \mathrm{hl}=\mathrm{pt}-$

BR\&sa=X\&scisig=AAGBfm0GMN54KQJaZ8yz0lfRYM3Kd9M6kw\&nossl=1\&oi=schol arr\&ved=0ahUKEwi0kfOx5erOAhUFIJAKHUh6ARMQgAMIGygAMAA >.

MATIAS, E. F. F.; SANTOS, K. K. A.; ALMEIDA, T. S.; COSTA, J. G. M.; COUTINHO, H. D. M. Atividade antibacteriana in vitro de Croton campestris A., Ocimum gratissimum L. e Cordia verbenácea DC. Revista Brasileira de Biociências., v. 8, n. 3, p. 294 - 298, 2010. Disponível em: <http://www.ufrgs.br/seerbio/ojs/index.php/rbb/article/view/1428>.

MATOS, F. J. A. Introdução à Fitoquímica Experimental. 2 ed. Fortaleza: Edições UFC, 1997. 141p.

MEISNER, J.; ISHAAYA, I.; ASCHER, K. R. S.; ZUR, M. Gossypol inhibits protease and amylase activity of Spodoptera littoralis larvae. Annals of the Entomological Society of America, v.71, n.1, p.5-8, 1978. Disponível em: < http://aesa.oxfordjournals.org/content/71/1/5 > doi: http://dx.doi.org/10.1093/aesa/71.1.5 
MONTEIRO, J. M.; DE SOUZA, LINS NETO, J. S. N.; E. M. F.; SCOPEL, K.; TRINDADE, E. F. Does total tannin content explain the use value of spontaneous medicinal plants from the Brazilian semi-arid region? Rev. bras. Farmacogn., v. 24, n. 2, p. 999-1005, 2014.Disponível em: < http://www.scielo.br/pdf/rbfar/v24n2/0102695X-rbfar-24-02-00116.pdf> doi: http://dx.doi.org/10.1016/j.bjp.2014.02.001

MELO, J. G. S. Rotala Ramosior (L.) Koehne (Lythraceae), Abordagem farmacognástica e atividade biológica. 2005. 84 f. Dissertação (Mestrado em Ciências Farmacêuticas) Programa de Pós-Graduação em Ciências Farmacêuticas, Universidade Federal de Pernambuco, 2005.

MUNDO, S. R. Caracteres Morfoanatômicos de folha e caule de espécies brasileiras de uso medicinal: Calophyllum brasiliense CAMBESS. (CLUSIACEAE), Cupania vernalis CAMBESS. (SAPINDACEAE) E L. pacari (LYTHRACEAE). 2007. 79 f. Dissertação (Mestrado em Ciências Farmacêuticas) Programa de Pós-Graduação em Ciências Farmacêuticas, Universidade Federal do Paraná, 2007.

MYERS, N.; MITTERMEIER, R. A.; MITTERMEIER, C. G.; DA FONSECA, G. A. B.; KENT, J. Biodiversity hotspots for conservation priorities. Nature., v. 403, n. 2, p. 853-858, 2000. Disponível em: < http://www.nature.com/nature/journal/v403/n6772/full/403853a0.html> doi: $10.1038 / 35002501$

PORFÍRIO, Z.; MELO-FILHO, G. C.; ALVINO, V.; LIMA, M. R. F.; SANT'ANA, A. E. G. Atividade antimicrobiana de extratos hidroalcoólicos de Lafoensia pacari A. St.Hil., Lythraceae, frente a bactérias multirresistentes de origem hospitalar. Rev. Brasileira de Farmacognosia., v. 19, n. 3, p.785-789, 2008. Disponível em: < http://www.scielo.br/scielo.php?script=sci_arttext\&pid=S0102-695X2009000500023> doi: http://dx.doi.org/10.1590/S0102-695X2009000500023

QUEIROZ-SILVA, S. M. F.; PINHEIRO, S. M. B.; QUEIROZ, M. V. F.; PRANCHEVICIUS, M. C.; CASTRO, J. G. D.; PERIM, M. C.; CARREIRO, S. C. Atividade in vitro de extratos brutos de duas espécies vegetais do cerrado sobre leveduras do gênero Candida. Ciência \& Saúde Coletiva., v. 17, n. 6, p. 1649-1656, 2012. Disponível em: < http://www.scielo.br/pdf/csc/v17n6/v17n6a28.pdf>

REGO, G. M.; BORTOLETO, A. S.; MASCHIO, W. Monitoramento da fenologia de espécies arbóreas das florestas brasileiras: dedaleiro. Embrapa. Colombo, 2009. Disponível em < http://www.infoteca.cnptia.embrapa.br/handle/doc/580629>. Acesso em: 10 Jun. 2015.

SAMPAIO, B. L.; BARA, M. T.; FERRI, P. H.; SANTOS, S. C.; DE PAULA, J. R. Influence of environmental factors on the concentration of phenolic compounds in leaves of Lafoensia pacari. Rev. Bras. Farmacogn., v. 21, n. 6, p. 1127-1137, 2011. Disponível em: < http://www.scielo.br/pdf/rbfar/v21n6/aop17811.pdf> doi: http://dx.doi.org/10.1590/S0102-695X2011005000177 
SANTOS, A. A.; SANTO, A. M. C. E.; BATISTA, M. C. A.; MOREIRA, L. R. M. O. Determinação Química dos Constituintes do Abacateiro (Persea Americana Mill). Revista Florence. v.1, n.1, p. 11-18, 2014. Disponível em: http://florenceemrevista.florence.edu.br/index.php/florence/about.

SILVA FILHO, M. C.; FALCO, M. C. Interação planta-inseto: adaptação dos insetos aos inibidores de proteinase produzidos pelas plantas. Biotecnologia: Ciência \& Desenvolvimento., $\quad \mathrm{v} 2, \quad \mathrm{n} 12, \quad$ p. $38-42, \quad 2000$. Disponível em:< http://www.biotecnologia.com.br/revista/bio12/interacao.pdf>

SILVEIRA, L. M. S.; OLEA, R. S. G.; MESQUITA, J. S.; CRUZ, A. L. N.; MENDES, J. C. Metodologia de atividade antimicrobiana aplicada a extratos de plantas: comparação entre duas técnicas de ágar difusão. Revista Brasileira de Farmácia., v. $90, \quad$ n. $2, \quad$ p.124 - 128, 2009. Disponível em: < http://rbfarma.org.br/files/pag_124a128_metodologia_atividades_239.pdf>.

SIMÕES, C. M. O.et al., ; Farmacognosia: da planta ao medicamento. $6^{\mathrm{a}}$ ed. Porto Alegre/Florianópolis: UFRGS editora/editora da UFSC, 2010, 1104 p.

YUNES, R. A.; CALIXTO, J. B. Plantas medicinais sob a ótica da moderna química medicinal. Chapecó: Argos, 2001.500p. 